\title{
Estudio breve de ideas socio-políticas, según el P. Feijoo
}

\author{
por SABINo ALVAREZ - GENDIN \\ Magistrado del Tribunal Supremo
}

Me propongo hacer un estudio de Sociología política, en sus más importantes obras, del P. Feijoo, ya que, hombre experimentado y utilizador de métodos inductivos en los estudios de las ciencias biológicas y médicas como él, ha de proporcionar frutos en sus ensayos o intentos de estudios en especiales materias, mảs o menos extensos, con conclusiones provisionales, o breves, sin que la conclusión entonces sea definitiva, no dejando de revelar este género literario-científico, que hoy llamamos ensayo, en materia social-política, y que tiene su encauce en el Teatro Crítico Universal y en las Cartas Eruditas dirigidas a los Reyes que gobernaron durante su redacción: Fernando VI y Carlos III, a altos personajes reales o personajes eclesiásticos y de la Corte, como, respectivamente, la Reina Doña María Bárbara de Portugal, el Obispo de Oviedo, D. Juan Avello y Castrillón, y el Duque de la Mirándola, Príncipe de San Martín.

No es posible redactar un trabajo científico y sistematizado, superior a la categoría también de ensayo, no ya por las pocas luces del 
ahora intérprete de los tratados al respecto redactados por Feijoo, la brevedad del tiempo para que llegue este ensayo al Simposio que celebra la Universidad de Oviedo, con ocasión de conmemorar el segundo centenario de la muerte de Feijoo, sino porque él no dio intensidad a tales estudios sociológico-políticos ni forjó estudios capaces para redactar una monografía erudita, verbigracia, como en materia médico-biológica, dedicando capítulos enteros al método curativo de la transformación de la sangre --como la que escribió Marañón en las Ideas biológicas de Feijoo-, o en materias físicas considerándose como un adelantado del atomismo (Masriera), o teológicas para combatir las supersticiones y los milagros supuestos, sin negar los racionalmente comprobados, a fin de "depurar la hermosura de la religión de vanas credulidades», o a las filosóficas, que, como reconoce Menéndez Pelayo, predominó la Filosofía Natural en el Teatro Crítico. ${ }^{1}$

\section{Demografía}

Se preocupaba Feijoo de problemas sociológicos, singularmente demográficos, como lo demuestra el análisis que en la $\operatorname{Carta~} \mathbf{X},(\boldsymbol{V}$, $\$ \$ 18-20)^{2}$ hace de la despoblación española, atribuyéndolo a la peste, incendios, inundaciones, años estériles, guerras, cextracción de gente hacia América», expulsión de los moros, etc.

El remedio que apunta es a largo plazo, como serían las medidas profilácticas sobre epidemias, impedir guerras, etc., lo cual para aumentar un millón o más de habitantes calculaba un siglo o algo más, pues, como agudamente dice, «ni podemos resucitar los que murieron en cam. paña en los hospitales, ni revocax (reintegrar a España) los que ha siglos salieron a otras tierras, ni aumentar los frutos calamitosos, ni suplir o reparar la disminución del número de habitantes, que provino de la falta de providencias políticas y económicas, conducentes a una numerosa prolificación.»

Así propugna por medidas protectoras de la agricultura, cual la constitución del Canal de Tierra de Campos para riegos.

1. Historia de los Heterodoxos españoles, tomo 1, p. 93, 1947. 


\section{Hechos históricos religiosos}

Al tratar de la defensa de la fe por los españoles viajantes o residentes en países extraños, en los que predominaban las sectas protestantes, relata la autoridad persecutoria $:^{3} a$ ) de Enrique VIII de Inglaterra, de la que fueron víctimas «los tres mayores y mejores hombres que produjo Inglaterra en aquella edad", el Canciller Tomás Moro, santificado por la Iglesia Católica; el Obispo de Rochester, Juan Fischer, y el Cardenal Reginaldo Pola, de los cuales los dos primeros perdieron la vida en el cadalso y el tercero se salvó, a pesar de los medios que puso Enrique VIII para quitársela, y de cuya muerte no se libró su primera amiga, Ana Bolena; ${ }^{4} b$ ) de su hijo Eduardo VI, cuya persecución no fue tan cruenta, limitándose a prohibir el uso del púlpito y el apostolado a los católicos; $c$ ) de Isabel I, que, menos sanguinaria que su padre, Enrique VIII, no deja de contar entre sus víctimas a María Estuardo, Reina de Escocia, y dice Feijoo, aun alegadas como móvil razones de Estado, que era muy verosímil que en su muerte tuviera no poco influjo el odio a su religión.

Después de estudiar el mitigado reinado de Jacobo I, respecto del bastante menos religioso de Carlos I y el de su hijo Carlos II, prudente rey, señaló Feijoo la monstruosidad observada con Jacobo II, hermano y sucesor de Carlos II, reprochando la falta de libertad de conciencia de los protestantes, que la proclamaban contra los príncipes católicos que no permiten la libertad de conciencia de sus súbditos, cuando no permitieron ellos la libertad de conciencia de su rey Jacobo II, que no quiso abandonar la profesión de la religión católica, al deponerle del Trono, y glosa diciendo:

«Rara invención de ideas. ¿Qué es esto sino constituir al Príncipe dependiente de sus súbditos, y a los súbditos superiores del Soberano?.. Quieren, sí, la tolerancia, pero una tolerancia sólo cómoda para ellos; quieren ser tolerados $\sin$ ser tolerantes. $x^{5}$

Y agrega que los protestantes rehusan tolerar la religión católica, pero toleran lo que es supremamente intolerable, la absoluta irreligión, la negación de todo culto y de la verdad, el ateísmo, y se refiere a la

2. Cartas, V, ps. 252 y sigts., 1761.

3. Cartas, V, $\S \S 4-4$, ps, $140-41,1761$.

4. Vid. Carta V, „Causa de Ana Bolenas, Cartas, IV, ps. 58 y ss., 1759.

5. Cartas, V, carta III, $\S \S 57,58$ y 59 , ps. $146-47,1761$. 
prohibición por parte del Tribunal británico de todos los libros favorables a la religión católica, dejando, en cambio, correr indemnes los que fomentan la impiedad.

Y en otro lugar de la Carta III (V, § 33) informa que en los países donde domina la religión católica, todas las sectas claman por la libertad de conciencia y llaman tiránico al Gobierno que lo deniega; pero - agrega - en los países donde la religión romana está abatida, cada secta aspira, según sus fuerzas, a la dominación sobre todas las demás, y, si llega a conseguirla, a todas las demás procura oprimir o desterrar, atribuyendo esta conducta a Lutero, que primero fulminó contra la autoridad del Papa y la Iglesia Romana; pero, una vez que engrosó su secta, trataba de herejes a los Sacramentarios, abominaba a los anabaptistas, despreciaba a Escolampadio y a Carlostadio, en suma, que tal conducta de las diversas sectas protestantes se sintetizan en este slogan - según deducimos de la opinión de Feijoo-: Los herejes claman por la tolerancia de la religión, si son dominados, y, si una secta es dominante, claman entonces contra todas las demás religiones.

\section{La Monarquía}

No era opuesto Feijoo al régimen monárquico, antes bien admira a sus reyes, Fernando VI y Carlos III, y les dedica sendas Cartas, pero anatematiza cuando tiene el origen de la Monarquía en la violencia, en la rebelión o en la perfidia, y así atribuye la de los asirios, la de los medas, la de los persas, la de los romanos. ${ }^{6}$

Así como alaba el Padre benedictino al Monarca héroe, no en cuanto a conquistador, en cuanto responde no al slogan de la grandeza del espíritu, ni de sus tierras, dice con Agesilao, que contesta a quien le ponderaba la grandeza del rey de Persia:

"Sólo puede ser mayor que yo quien fuera mejor que yo"; así celebra, como Herodes a Teodosio, a Carlo Magno - si bien tuvo fragilidades de hombre-, a Godofredo de Bullón, a Jorge Castrioto; que servían al valor y el valor a la justicia a quienes sólo arrancaba la espada de la cinta o el interés del Cielon.?

6. Teatro, II, Disc. VII, $\S \S 18$ y sigts.

7. Teatro, IV, Disc. XIII, §§ 39-40, y III, Disc. XII, $\S 14$ y 15. 
de donde el elogio de Fernando III, que gobernó en paz y justicia, juntó las dos Coronas de Castilla y León, ganó para Castilla y para los cielos los reinos de Murcia, Córdoba y Sevilla, estableció el Supremo Consejo de Castilla, instituyó excelentes leyes y empezó la colección de la de las Partidas que continuó su sucesor e hijo, Alfonso X.

Por análogas razones justificaba nuestra conquista de América y como por ello entona cantos de elogio para los Reyes Católicos y Car$\operatorname{los} I,{ }^{8}$ que fueron pacíficos por inclinación y guerreros por necesidad.

También hace Feijoo el elogio de Cisneros por abatir o reprimir el orgullo de los grandes.

Respecto de los tiranos, de estas severas y contundentes palabras feijonianas se deriva toda resistencia: "Derríbense sus estatuas, o trasládense sus imágenes del palacio a las casas de fieras, por que esté siquiera la copia donde debiera haber estado el original.» Así, pues, hace el elogio de tres emperadores romanos nacidos en España: Trajano, Adriano y Teodosio, sin que su patriotismo español le impida ver como lunar en éste permitir la destrucción de Tesalónica, por sus legiones, para castigar la muerte de un lugarteniente general, reconociendo del gran Teodosio el haber abatido la ideología que se apoderó de Roma en tiempos de Juliano el Apóstata, que sucedió en el Imperio a Constancio, hijo de Constantino, que otorgó la paz a los cristianos en el Edicto de Milán. ${ }^{10}$

\section{Conceptos de la Nobleza}

Es sumamente interesante el estudio que hace Feijoo en su Teatro Crítico, en el Discurso II del tomo IV," «Valor de la Nobleza e influjo de la Sangre».

8. De Fernando el Católico decía Feijoo que era el más consumado y perito en el Arte de reinar, reputada por grandes Maestros de la Política. De Isabel elogia Feijoo su perspicacia, su valor, que la colocaron muy superior a las ordinarias facultades de nuestro sexo, por cuya razón no hay quien no la estime por uno de los más singulares ornamentos que ha logrado el suyo (Teatro, IV, Disc. XIII, $\$ 382,83$ y 88 ).

9. Ob. cit., loc. y arts. § 16 .

10. Teatro, IV, Disc. XIII, §̧ 38-42. 
Elogia la nobleza, no porque en las generaciones se transmita el genio y las costumbres - de padres a hijos-, porque en cada generación hay alteraciones sensibles bastantes para introducir desemejanza respecto del progenitor inmediato, y en el círculo de muchos viene a ser la desemejanza tan grande como si no hubiera algún parentesco.

Pero estima que el noble que es honrado, por sus virtudes, influye en los suyos para continuar la virtud; pero ello no quiere decir que, según doctrina constante de Aristóteles y Santo Tomás, mucho más se debe honrar la virtud recaida en un plebeyo que al noble que carece de virtud. ${ }^{12}$

Dicho discurso merecía un especial apartado que me impide hacer el tiempo que falta para el homenaje que dedica Oviedo y su Universidad a Feijoo.

\section{La adulación}

Señala nuestro Padre benedictino el mal que se hace a los reyes con la adulación, con la que éstos - como Luis XIV de Francia- abusaban del pueblo imponiéndoles contribuciones y sacrificios, a millaradas en las aras de Marte, de las vidas de sus vasallos.

Aunque no ve más perjudicial la adulación de los humildes a los poderosos que la de los poderosos a los humildes. Es el caso del gobernante demagogo, que adula al pueblo para que le erija en alto o le mantenga en el poder.

"La moneda - dice Feijoo agudamente- que todos tienen a mano para comprarse los corazones es la de la lisonja, moneda la más falsa de todas, y por ello todos salen enganados en este vilísimo comercio., ${ }^{13}$

¡Cuántas enseñanzas del saber de este benedictino debemos apropiarnos para ser buenos gobernantes y no peores gobernados!

11. Ed. 1759, págs. 26-40.

12. Teatro, IV, Disc. II, $\S 26$.

13. Teatru, VI, Disc. IX, $\$ \S 14$ y 15. 


\section{Mapa intelectual y Cotejo de las Naciones}

Dedica Feijoo todo el Discurso XV del tomo II de su Teatro Crítico, con el precedente título, al examen de las características de las naciones, negando la influencia de causas naturales, entre otras el clima, en la mayor o menor acentuación de la agudeza de las Naciones, por lo que no puede inferirse desigualdad en el predominio que tiene el temperamento ni ninguna de las cualidades sensibles, pues yerran los que creen que los países húmedos y nebulosos producen espíritus groseros, y al contrario en los secos y despejados, pues todo ello depende, según el benedictino, de causas inaccesibles a nuestros conocimiento, por lo menos no comprendidas hasta ahora, aunque no niega, pues, que pueda haber causas naturales que influyan en la naturaleza de los pueblos.

$\mathrm{Y}$, para contradecir la tesis de que en países lluviosos se forjan tipos de hombres torpes, cita el caso de Asturias, en cuya región se nota por lo común genios más despejados. ${ }^{14}$ En todo caso, la humedad proporciona inquietud de espíritu, para producir cierto humorismo agudo, como en nuestros literatos, Clarín, Palacio Valdés, Ochoa Tuero, Pérez de Ayala, Casona, e igualmente en el pueblo, a lo que contribuye no poco la sidrina.

No desdeña Feijoo $^{15}$ el amor a la provincia, a la diócesis, a la ciudad, al distrito, donde nace cada uno, y se llama patria particular -diremos patria chica o de campanario-, pero sublima la patria nacional, la República, el Estado, diciendo que no es el amor a la patria el tomado en el sentido anterior - patria particular-, sino en el nacional, el que califican con ejemplos, persuasiones y apotegmas, historiadores, oradores y filósofos.

La patria, dice el Padre,

«a quien sacrifican su aliento las almas heroicas, a quien debemos estimar sobre nuestros particulares intereses, la acreedora a todos los obsequios posibles, es aquel cuerpo del Estado donde debajo de un Gobierno civil estamos sumidos con la coyunda de una misma ley. Así España es objeto propio del amor del español; Francia, del francés; Polonia, del polaco."

Hermosa definición de patria, si bien enmarcada en los dominios políticos, en cuyo caso no habría irredentismo de patria o trozos de

14. Teatro, II, Disc. XV, $\S 32$ y 33 .

15. Teatro, III, Disc. $\mathrm{X}, \$ 30$. 
patria -en el sentido histórico y de comprensión de afinidades religiosas, idiomáticas y étnicas-, cuyo más típico ejemplo fue y es Polonia, tantas veces descuartizada y hoy mismo desgajada por Rusia, el norte del país, si bien le hayan incorporado al sur tierras de otra patria, de Alemania, después de la segunda guerra mundial.

\section{Política o Arte de gobernar}

En el tomo VI de su Teatro Crítico, en el Discurso I, plantea Feijoo cuestiones que denomina paradojas políticas y morales, es decir, de la oportunidad de aplicar medidas de Gobierno, auténtico arte de gobernar, que merecerían cuidadosos comentarios que no tenemos tiempo de hacer. Así, expone que la multitud de días festivos es perjudicial al interés de la República, y nada conveniente a la región, proposición que hoy deberíamos tener presente ante la multitud de festividades profanas establecidas.

Considera la clemencia de los príncipes como perniciosa respecto de los pueblos, con la explicación de que, si la ley penal es justa, entonces resulta el gobernante protector de maldades, tirano indirecto de la República, al aflojar la mano en los castigos de los delitos.

La Paradoja 6. ${ }^{a}$ del Discurso I, del Teatro Crítico, tomo VI, encabeza con el siguiente epígrafe: "La edad corta es menos favorecida de lo que debiera ser, en la promoción de ejemplos". Sin embargo, en el desarrollo del tema señala ejemplos de jóvenes prodigiosos, a quienes no igualan los octogenarios, mencionando a Pico de la Mirándola, Fernández de Córdoba, Hugo Gracia y otros más. ${ }^{16}$

No opta por la edad provecta para regir pueblos, dirigir guerras, etcétera, sino que preferiría la edad media a la ancianidad, porque prevalece en aquélla el vigor del alma y cuerpo, importantísimo uno y otro para la buena administración de cualquier empleo.

Concluye su disertación diciendo "que para los públicos empleos es enfermiza la juventud, y mucho más la vejez; pues, si en los jóvenes

16. Loc, cit., núm. 69. 
cunde la ira y la pasión, en los ancianos la avaricia y la codicia». Por eso se inclina Feijoo por las personas de media edad para ocupar cargos que diríamos hoy de responsabilidad. ${ }^{17}$

En la Paradoja 8. ${ }^{a}$, del Discurso del Teatro que venimos comentando, se inserta este epígrafe: "Debiera hacerse constar al Magistrado de qué se sustentan todos los individuos del pueblo, para limpiarlos de innumerables sabandijas que le infectan».

Pero, sobre todo, estos juicios de residencia, seguidos en el período de descubrimiento y conquista de América con los virreyes, oradores y altos mandos en general, debieran tener eco en todos los tiempos para cuantos han ocupado cargos públicos, y hubiéramos visto caer de pedestales de oropel a muchos personajillos políticos y administrativos.

\section{Vidas paralelas de Reyes y Caudillos}

1. En la Carta XIX del tomo I de las Cartas Eruditas estudia paralelamente, siguiendo el método plutarquiano, la vida de Carlos XII, rey de Suecia, y de Alejandro el Grande, y alabando los hechos heroicos militares y los actos políticos de ambos gobernantes, distantes en el tiempo y en el espacio, concluye ensalzando las condiciones del primero; pues, si bien equipara en virtudes a ambos magnates, hasta el punto de llamar a Carlos XII el Alejandro del Norte, se inclina por Ja exaltación del primero, pues, si ambos poseyeron idénticas virtudes, Carlos XII carecía de los vicios contra continencia y contra templanza, de los que sí podía vanagloriarse Alejandro de Grecia, y, con todo, a las guerras que sostuvo Carlos XII las considera justas Feijoo, cosa que no sucedió con todas las promovidas por Alejandro, así con los atenienses y tebanos, que, si se rebelaron contra él, fue por recobrar las tierras que había usurpado Felipe, padre de Alejandro.

2. Al hacer un paralelo entre nuestro Carlos I y V de Alemania y Francisco I de Francia, en el Teatro Crítico, ${ }^{18}$ describe nuestro homena-

17. Loc. cit., núm. 74 .

18. II, Disc. 9, $§ \S 7$ y 8 . 
jeado la rivalidad entre españoles y franceses, nacida de la rivalidad de los alemanes con los franceses y que aquéllos, al reinar Carlos en España, insertaron o transmitieron a los españoles, nacidos de disensiones; familiares entre las casas reinantes, y que entre Francia y Alemania permanecieron hasta la segunda guerra mundial; no así entre España y Francia, a partir de Felipe V, de la dinastía de Borbón, salvo el paréntesis de la guerra de la Independencia, al menos por lo que respecta a nosotros, inclinados a olvidar vejaciones, y con menos complejo de superioridad que nuestros vecinos de allende los Pirineos.

Tal rivalidad la consideró incrementada por el apoyo de los franceses a los rebeldes de Holanda, en tiempos de Felipe II, pese a la tendencia a la Reforma de estos súbditos nuestros y a la catolicidad de los franceses, salvo el sector hugonote.

Quizás exagera Feijoo en los puntos de vista de oposición entre franceses y españoles. Caracteriza entre sí, influyendo en la naturaleza de uno y otro país, al examinar su coetáneo mundo, sin que ello baste para otear el porvenir político y social, que no confirmó tal encendida rivalidad.

3. En la Carta XIX del tomo III, hace Feijoo un parangón entre Luis XIV, rey de Francia, y Pedro I el Grande, zar de Rusia, en la que revela los vicios y virtudes de ambos, más reducidos aquéllos en el zar que en el rey de los franceses, y exaltando las virtudes de aquél, pese a la mejor educación del rey que la del zar, la de aquél formada en la religión católica y la de éste en religión llena de errores, y concluye haciendo este panegírico del emperador ruso:

"Se instruyó en varias Ciencias y Artes, de modo que fue Matemático, Filósofo excelente, General de las Tropas de Tierra, habilísimo Almirante de las de Mar, Político insigne e Historiador, Piloto, Aquitecto Naval, etc. ¡Raro genio! ¡Portentosa capacidad!»

\section{Historia magister vitae}

No se apasiona Feijoo por la Historia como maestra de la vida política, pues no hace políticos el estudio de la Historia a quienes no lo sean 
por genio y naturaleza; pero no deja de reconocer sus buenos servicios y utilidad al que tuviere prendas naturales, necesarias, ya porque le da en general más conocimiento de la variedad de los genios de los hombres, ya porque la lectura de muchos y extraños sucesos hará que no le sorprendan los ulteriores, ya porque los altos y bajos de la fortuna, que se presentan a cada paso en la Historia, le harán cauto para no fiarse mucho en la suya, en su suerte. ${ }^{19}$

También Feijoo fía mucho en la ciencia y en el saber, para ser político selecto, y así dice:

"Algunos, muy aplicados a la lectura de Hipócrates, salen muy malos médicos; como otros que tienen en la una todas las Máximas de Saavedra, muy infelices políticos; y es que uno y otro Arte requieren, fuera de los preceptos generales, una prudencia sagaz que, hic et nunc, represente lo que se ha de hacer y cómo se ha de hacer.»20

Cierro esta selección de ideas y antología de sentencias sociológicas y políticas del polígrafo gallego P. Benito Jerónimo Feijoo, al rendirle homenaje en el segundo centenario de su muerte, para ejemplo y modelo propio $\mathrm{y}$, sobre todo, de políticos y administradores presentes $\mathrm{y}$, en general, para enseñanza de las venideras generaciones.

19. Teatro, V, Disc. X $\S 34$.

20. Cartas, 1.0, cartas XIV. 